\title{
ATENÇÃO PSICOSSOCIAL EM ENFERMAGEM \\ PARA FAMÍLIAS DE ALUNOS DO ENSINO FUNDAMENTAL
}

\author{
PSYCHO SOCIAL ATTENTION IN NURSING \\ TO THE FAMILY OF PUPILS OF BASIC EDUCATION \\ ATENCIÓN PSICO-SOCIAL EN ENFERMERÍA (PARA) A LA FAMILIA(S) \\ DE ALUMNOS DE LA ENSEÑANZA BÁSICA
}

Hellen Roehrs*

Mariluci Alves Maftum**

\footnotetext{
* Enfermeira. Especialista em Saúde da Família. Aluna do Curso de Mestrado em Enfermagem da Universidade Federal do Paraná. Membro do Núcleo de Estudo, Pesquisa e Extensão em Cuidado Humano de Enfermagem (NEPECHE/UFPR).

** Enfermeira. Doutora em Enfermagem. Professora do Departamento de Enfermagem da UFPR. Pesquisadora do NEPECHE/UFPR.
}

RESUMO. Este artigo refere-se a um relato de experiência da implementação de um projeto de Atenção Psicossocial em Enfermagem junto família de alunos do Ensino Fundamental, com dificuldades de relacionamento e/ ou mudanças de comportamento, em uma escola estadual do município de Curitiba. O objetivo é realizar entrevista de ajuda contribuindo, com na busca de soluções e enfrentamento de momentos de angústias na dificuldade de relacionamento e/ou mudança de comportamento de seus filhos adolescentes. O projeto vem sendo desenvolvido desde maio de 2005. O embasamento teórico dá-se na Teoria das Relações Interpessoais de Joyce Travelbee e na Entrevista de Ajuda preconizada por Alfred Benjamim. As dificuldades comumente trazidas para serem compartilhadas no encontro com o enfermeiro são: dificuldades de relacionamento com o filho e outros membros da família, baixo rendimento escolar, educação dos filhos, sexualidade, falta de autoridade dos pais e drogas. No pouco tempo da implementação já foi possível constatar a importância da proposta pela agregação de mais sujeitos ao projeto os quais se prontificaram a participar da discussão e das atividades desenvolvidas junto às famílias. Tal atitude deu um novo desenho à proposta inicial. Também, observouse a aceitação da proposta em virtude do retorno dos familiares aos encontros. Isso confirma o fato de que o enfermeiro pode promover a saúde das pessoas, agindo com competência, para mudar a realidade de cada um.

PALAVRAS-CHAVE: enfermagem; atenção psicossocial; estudantes; família.

ABSTRACT. This article is a experience report of the implementation Psycho-social Attention in Nursing's project with relatives of pupils from high school, that presents difficulties of relationship and or behavior' changes in a public school of Curitiba city - Brazil. The objective is to carry out an interview that can at same time offers some aid, contributing in search solutions and face aguish moments because of the difficulty of relationship and/or change of behavior of its adolescent children. The project has been developed since May of 2005. The theoretical base is sustained in the Theory of the Interpersonal Relations of Joyce Travelbee and in the Interview of help commended by Alfred Benjamim. The difficulties brought to be shared with the nurse are: relationship with the son and other members of the family, low score at school, children education, sexuality, lack of authority of the parents and drugs. During the short space of time of the implementation it was already possible to evidence the importance of the proposal for the aggregation of more people toward the project which wanted to participate on the discussion and the activities wiyh the families. Such attitude gave a new direction to the initial proposal. It also was observed the proposal acceptance because of the return of the familiars to the meeting. This confirms that the nurse can promote people's health acting with competence to change the reality of each one.

KEYWORDS: nursing; psycho social attention; students; family.

RESUMEN. Este articulo trata de un relato de experiencia de implementación de un proyecto de Atención Psicosocial en Enfermería junto a las familias de alumnos de la enseñanza básica, que tienen dificultades para se relacionar y/o mudanzas de comportamientos, en una escuela pública de la ciudad de Curitiba. El objetivo es realizar entrevistas de ayuda contribuyendo con la busca de soluciones y enfrentamientos de momentos de angustia en la relación y/o mudanzas de comportamientos de sus hijos adolescentes. El proyecto esta siendo desarrollado desde mayo de 2005. Con base teórico en la Teoría de as Relaciones Interpersonales de Joyce Trabelvee y en la Entrevista de Ayuda citada por Alfred Benjamín. Las dificultades que comúnmente trajeron para el encuentro de Enfermeros son: Dificultades de relación con el hijo y otros miembros de la familia, bajo rendimiento escolar, educación de los hijos, sexualidad, falta de autoridad por parte de los Padres y drogas. En el poco tiempo de implementación ya fue posible ver la importancia de la propuesta por la llegada de más personas al proyecto, los que se ofrecieron a participar de la discusión y de las actividades desarrolladas junto a las familias. Tal actitud trazo un nuevo diseño a la propuesta inicial. También se observó la aceptación de la propuesta debido al retorno de los familiares en los encuentros. Eso confirma el hecho de que el Enfermero puede promover la salud de las personas, actuando con competencia para mudar la realidad de cada uno.

PALABRAS-CLAVE: enfermería; atención psico-social; estudiantes; familia.

Recebido em: 27/10/2005

Aceito em: 09/12/2005
Hellen Roehrs

Rua General Carneiro, 181 - Centro

80060-900 - Curitiba - PR - Fone: (41) 3360-1800

E-mail: hellenroehrs@yahoo.com.br 


\section{INTRODUÇÃO}

Ao conhecer e descobrir os espaços da escola, os sujeitos que os freqüentam bem como a sua dinâmica das relações interpessoais, deparei-me sucessivamente com a clientela de crianças, adolescentes, jovens adultos e ainda por vezes com seus pais. Isso ocorreu, ao iniciar as minhas atividades como docente do Curso Técnico em Enfermagem, em uma escola estadual de Curitiba, que fornece o curso profissionalizante, Ensino Fundamental e Médio. Compartilhei os aspectos relacionados a essa idade e também os concernentes às dificuldades de relacionamento dos estudantes com seus professores e seus pais, assim como as dificuldades de aprendizagem, e a aproximação e uso de drogas, com minha mãe que é coordenadora pedagógica de outra instituição. Estes acontecimentos remeteram-me a uma intensa reflexão pessoal a respeito de como eu, enfermeira docente, poderia contribuir com a escola e com a comunidade local de forma significativa, uma vez que concebo que o papel do educador enfermeiro, é mais do que repassar informações, antes, é o conhecimento sendo compartilhado e construído para estabelecer modos de vida satisfatórios e produtivos para as pessoas e conseqüentemente a sociedade.

Nesse sentido, com o propósito de analisar a melhor forma de realizar tal contribuição, solicitei uma reunião à diretora da escola na qual expus as minhas inquietações e questionamentos. A diretora então relatou as dificuldades que identificava nos pais de alunos, principalmente os do Ensino Fundamental a partir da $5^{\mathrm{a}}$ série, cuja faixa etária predominante encontrava-se entre 10 e 15 anos. Referiu que alguns pais procuraram-na com o objetivo de obter ajuda e orientações para a resolução de conflitos relacionados à educação geral de seus filhos, em especial, quanto ao consumo de drogas, e, que a maioria destas crianças apresentava dificuldades no aprendizado e tinha demonstrado mudanças de comportamento em seu cotidiano.

Esses estudantes encontravam-se na adolescência, que é caracterizada por uma fase crítica, pelas dificuldades inerentes à transição entre deixar de ser criança, e o desejo e idealização do jovem em tornar-se adulto, é um período marcado por intensos conflitos e persistentes esforços de auto-afirmação. Nesta etapa, é possível observar o amadurecimento sexual, o aumento da responsabilidade pessoal, a busca de si mesmo e de identidade, uma separação progressiva dos pais, a diminuição da autoridade paterna, as constantes flutuações de humor e do estado de ânimo. Todos estes fatores podem estar permeados e intensificados pela ansiedade, medo do fracasso, além dos conflitos internos os quais podem gerar dificuldades no relacionamento entre os pais e os adolescentes ${ }^{1}$.

Devido à magnitude dos problemas que envolve a adolescência e a relação interpessoal entre pais e seus filhos nessa faixa etária, a diretora relatou-me, que se sentia limitada para contribuir de maneira satisfatória com os pais que freqüentemente procuram por ajuda na escola. Ressaltou, que o mesmo acontece com os demais educadores que não conseguem ajudá-los plenamente. O que vem a exigir também, a intervenção de profissionais de outras áreas, como por exemplo, os da saúde. Muitas causas dos complexos problemas existentes, comuns na adolescência, surgem em decorrência de fatores psicológicos, biológicos e relacionais, o que vem exigir, a intervenção de profissionais da área da saúde.

As enfermeiras, como profissionais da área de saúde, podem auxiliar pessoas a darem sentido às suas vidas, ao incluir em suas atividades profissionais a participação dessa clientela em programas de terapia de grupos ou de outro tipo de terapia, na relação pessoa a pessoa, com sessões de orientação. Ela pode atuar em conjunto com profissionais de outras áreas da saúde, das ciências sociais e humanas, como os da Medicina, Psicologia, Terapia Ocupacional, Fisioterapia, Serviço Social entre outros e também junto a educadores e ao poder legislativo e judiciário ${ }^{2}$.

Diante do exposto, busquei em Alfred Benjamin ${ }^{3}$ os conhecimentos acerca da entrevista 
de ajuda, por considerar que seria possível desenvolver ações com embasamento nesta temática. Para esse autor, a entrevista de ajuda possui o objetivo de desenvolver um relacionamento caracterizado pela confiança mútua e mudança criativa. Consiste em um diálogo sério e com propósito entre duas pessoas a fim de conseguir estabelecer um relacionamento terapêutico. Pois ela tem a função de utilizar e otimizar os recursos da própria pessoa de forma que compreenda melhor o que está acontecendo a si mesma.

Desta forma, implementei uma proposta de atenção psicossocial a qual desenvolvo mediante a técnica de entrevista de ajuda proporcionando acolhimento, ajuda e cuidado profissional de enfermagem, identificando as dificuldades de relacionamento entre pais e filhos, vividos pelos pais dos alunos de $5^{\mathrm{a}}$ a $8^{\mathrm{a}}$ séries do Ensino Fundamental.

A concepção de cuidar sustentada no modelo psicossocial ${ }^{4}$ é compreendida como o cuidado que extrapola os aspectos clínicos de uma patologia ou transtornos. Ela coloca a pessoa como centro do cuidado, seu problema ou doença não são negados, porém é o Ser que ganha destaque, a sua subjetividade, a sua história de vida com suas crenças, valores e visões de mundo, como alguém que faz parte de um contexto social concebido como espaço de organização de uma dada população que sofre influências de seus integrantes e, por isso, extrapola a noção de espaço geográfico. Traz também a compreensão de projeto terapêutico individualizado o qual é estabelecido entre o profissional e a pessoa que necessita de cuidado.

Assim este artigo traz o relato de experiência de uma prática profissional de enfermagem que teve por objetivo contribuir, com os pais, na busca de soluções e enfrentamento de momentos de angústias na dificuldades de relacionamento e/ou mudança de comportamento de seus filhos adolescentes.

\section{REFERENCIAL TEÓRICO}

Vale destacar, inicialmente, que o adolescente é um ser que se encontra em uma fase peculiar do desenvolvimento humano e, como tal, deve ser percebido em nosso contexto, com características biopsíquicas, intelectuais e emocionais específicas, enfrentando toda a sorte de infortúnios de uma sociedade em rápido processo de transformação.

A adolescência é considerada como uma etapa de transição entre a infância e a idade adulta e é marcada pelas mudanças e transformações no corpo físico e psíquico ${ }^{5}$. O Estatuto da Criança e do Adolescente (ECA), considera criança, a pessoa até 12 anos de idade incompletos e, adolescente aquela entre 12 e 18 anos $^{6}$.

A puberdade impõe ao adolescente grandes alterações e, desta forma, ele necessita adaptar-se às novas dimensões e experimentar, com atenção, as novas sensações para integrá-las no seu cotidiano ${ }^{7}$. As alterações físicas começam a surgir, para alguns, a partir dos 11 anos, sendo caracterizadas pela aceleração e desaceleração do crescimento físico, mudança da composição corporal, aumento dos níveis hormonais, sendo responsáveis pelo desenvolvimento sexual ${ }^{8}$.

Essas transformações constituem a síndrome da adolescência normal, que tem características de busca da identidade, tendência grupal, desenvolvimento do pensamento conceitual, vivência temporal singular, evolução da sexualidade, existindo, em algumas situações, um desacerto entre o corpo pronto para a reprodução e a mente despreparada para este acontecimento ${ }^{8}$.

Durante o caminhar do adolescente para a idade adulta, ele passa por vários momentos de dúvidas, desilusão, solidão e transformação. Considero que a família é unidade primária de cuidado e educação dos filhos, assim, é importante que toda a família esteja, adequadamente, informada do seu papel no desenvolvimento sadio da criança e do adolescente, bem como todos os seus membros, para que possa desempenhá-lo de forma adequada e harmônica ${ }^{8}$. Em uma pesquisa realizada com adolescentes por Cardoso e $\operatorname{Cocco}^{9}$, foi constatado que a maior parte das famílias não estão suficientemente preparadas para debater os assuntos referentes à sexualidade e 
drogas com os seus filhos. Esta responsabilidade educacional fica sendo entendida pelos pais, como função dos profissionais de saúde das Unidades Básicas de Saúde (UBS) e dos professores, nas escolas. Entretanto, foi comprovado, que estes profissionais também possuem dificuldade em abordar assuntos relacionados a estes temas ${ }^{9}$.

Independente do entendimento de a quem cabe a responsabilidade da discussão dos assuntos referentes à sexualidade, drogas ou outros inerentes à fase da adolescência, a relação interpessoal geralmente interfere no modo como as pessoas vivem e expressam suas vivências e preocupações. Portanto, por meio do diálogo é que os pais poderão encontrar um caminho para melhor conduzirem a educação e o desenvolvimento dos seus filhos.

Esse acesso pode ser facilitado pela entrevista de ajuda, baseada em Alfred Benjamin, a qual possui como objetivo desenvolver um relacionamento caracterizado pela confiança mútua e mudança criativa e efetivado mediante um diálogo sério e com propósito entre duas pessoas a fim de conseguir estabelecer um relacionamento terapêutico ${ }^{3}$.

A relação interpessoal de acordo com Joyce Travelbee se traduz pela existência de um sentimento de confiança no vínculo estabelecido entre o enfermeiro e a pessoa, então esta será capaz de revelar seus sentimentos mais íntimos e seus problemas, tendo a esperança, de sair beneficiado da relação ${ }^{2}$. Será nessa aproximação que o profissional verifica com freqüência que os familiares se omitem em discutir assuntos concernentes a sexualidade, drogas, violência e a influência dos meios de comunicação com as crianças e adolescentes ${ }^{1}$.

\section{METODOLOGIA}

Este projeto vem sendo desenvolvido desde maio de 2005, sendo destinado horários de permanência do enfermeiro na escola para que os pais que necessitam dialogar a respeito de suas relações com seus filhos possam fazê-lo tendo assegurado um local e horários próprios.
O local em que são desenvolvidas as atividades da proposta é um Colégio da Rede Pública Estadual de Ensino de Curitiba, o qual oferece Ensino Fundamental, Ensino Médio e Curso Profissionalizante de Técnico em Enfermagem. Atualmente, esse estabelecimento conta com 65 turmas, totalizando aproximadamente 2.925 alunos, distribuídos no Ensino Fundamental 2.250 alunos, Ensino Médio 540 alunos e no Curso Profissionalizante de Técnico em Enfermagem 135 alunos, sendo que seu corpo docente é composto por 80 professores; destes, 45 possuem Licenciatura Plena, enquanto que os outros 35 possuem além da Licenciatura Plena, cursos de Pós-Graduação latu sensu. Para o Curso Técnico em Enfermagem há sete enfermeiros docentes.

\section{DESCRIÇÃO DO PROCESSO}

FASE INICIAL

O primeiro contato ocorreu em março de 2005 ao iniciar minhas atividades como docente no curso de Técnico em Enfermagem que a escola oferece, e na ocasião submeti a uma entrevista com a diretora. Esta mencionou a inexistência de qualquer trabalho junto aos pais, considerando relevante o desenvolvimento de ação preventiva enfocando o consumo de drogas. Explicou ainda, que os pais, muitas vezes, procuramna para relatar as dificuldades de relacionamento com seus filhos, referindo falta de autoridade, dificuldade de diálogo familiar, envolvimento dos filhos com drogas, entre outros. Relatou que a coordenação pedagógica também atua identificando as crianças que apresentam dificuldades de aprendizado ou mudanças de comportamento em sala de aula, para investigar o porquê destas ocorrências. Indicou que, na maioria das vezes, as causas estão relacionadas com conflitos próprios da idade, dificuldade de relacionamento com os pais, tais como processo de separação, desestruturação familiar e envolvimento com drogas.

Em decorrência ao exposto por ela, propus desenvolver este projeto visando oferecer ajuda aos pais que possuem dificuldade de relacionamento com 
os filhos adolescentes, na modalidade da entrevista de ajuda individualizada. Para tanto esclareci que os encontros individuais entre o enfermeiro e os pais seriam registrados e organizados em arquivos individuais do pesquisador. Esses encontros seriam previamente agendados de acordo com a possibilidade de tempo de cada um e aconteceram semanalmente durante aproximadamente um mês.

Os conflitos que esses pais vivenciam, caracterizam-se pela existência de desequilíbrio entre a intensidade do problema e as forças re-equilibradoras, necessitando de auxílio no favorecimento de contatos interpessoais, que poderão contribuir para a resolução dessa situação ${ }^{4}$.

Devido à complexidade da problemática apresentada, a sensibilidade, experiência e formação profissional, constata-se que os profissionais, muitas vezes apresentam limitações frente a estas ocorrências as quais envolvem o ser humano como um todo ${ }^{4}$. Diante dessas limitações, sugeri trabalhar em conjunto, educadores e profissionais de saúde, para atender os pais. Eles devem receber atenção adequada, eficiente e resoluta que os ajude a superar a crise, fortalecendo-os para que possam resolver seus problemas e adotar uma postura mais sadia e harmônica ${ }^{4}$.

Acredito que este estudo pode contribuir para o ensino de futuros profissionais de enfermagem a respeito das possibilidades de ações de atenção primária, pois cada vez mais há necessidade destes atuarem na comunidade prevenindo riscos de forma integral, eficiente e resoluta. Algumas pesquisas mostram a participação desses profissionais em trabalhos realizados em comunidades, junto às pessoas com dificuldades ${ }^{4}$.

\section{ALICERCE TEÓRICO}

A entrevista de ajuda é a ampla interação verbal e não verbal entre o enfermeiro e a pessoa, na qual se dá o ato de capacitação ${ }^{3}$, e, o ato de ajudar é um ato de capacitação, visto que o enfermeiro pode capacitar a pessoa a reconhecer, sentir, saber, decidir, escolher se deve ou não mudar, e, que esta pessoa recebe ajuda adequada e expressiva para ele no decorrer da relação.

Outro aspecto importante na entrevista de ajuda é a empatia. O enfermeiro precisa ser empático com a pessoa com quem está se relacionando, participar do mundo dela, sentir sua estrutura interna, ver por meio dos olhos dela. Durante a entrevista, o enfermeiro poderá compartilhar os pensamentos e sentimentos como se fossem dele, pois ele fez o possível para compreendê-los, sem se influenciar de modo negativo com eles.

Baseado ainda, na premissa de que os pais possuem a função de educador e transmitem sua herança cultural para os filhos, e que eles, também adotam até mesmo de maneira inconsciente os padrões culturais estabelecidos pela sociedade ${ }^{10}$, percebe-se que necessitam de informações referentes à fase que seus filhos estão vivendo, pois algumas vezes, mostram-se despreparados para interagir com seus filhos durante a adolescência, tendo em vista o fato de que esta etapa do ciclo vital é caracterizada por transformações. Neste período os pais devem possibilitar a seus filhos uma educação baseada na discussão de suas preocupações, expectativas, medos, anseios, sentido de vida, oportunizando a suas tomadas de decisões e de escolhas mais adequadas, promovendo assim, sua saúde e bem estar ${ }^{8}$.

\section{A ENTREVISTA DE AJUDA}

Após obter o consentimento da diretora para o desenvolvimento da proposta, discutimos e decidimos expô-la para a comunidade escolar em duas reuniões de pais, que seriam convocadas por ela para entrega boletins de notas. A primeira reunião aconteceu no período da manhã e outra no período da tarde, para os pais dos alunos dos respectivos turnos. Participei das reuniões, quando expliquei como seria desenvolvido o projeto, bem como quais eram seus objetivos. Esclareci que a partir daquele mês, eu, 
enfermeira docente do Colégio, passaria a receber os pais, ou outro parente responsável pelos adolescentes, com horário e dia previamente agendado, para conversarmos sobre assuntos que eles sentissem necessidade de compartilhar e receber ajuda de um profissional de enfermagem.

Esclarecido o projeto, coloquei-me à disposição para maiores informações e para o agendamento de horário. No final de uma das reuniões, duas mães me procuraram e marcaram horário para serem atendidas, sendo que me anteciparam o assunto que gostariam de compartilhar. Disseram-me que a maior dificuldade que sentiam era a de falar com suas filhas sobre sexualidade, pois não sabiam como deveriam agir na educação sexual delas.

Ao término da segunda reunião, uma senhora me procurou e se identificou como moradora da região e integrante da associação de moradores do bairro. Ela relatou que o projeto vinha ao encontro das necessidades da comunidade, pois na sede da associação, ela havia vivenciado atendimento com pais que apresentavam dificuldade de relacionamento com seus filhos e o seu envolvimento com drogas, entre outras situações. Informou ainda, ter interesse em participar, como voluntária, do projeto e indicou uma enfermeira da comunidade para participar. Achei importante, visto que naquele instante a equipe de trabalho estava sendo ampliada. Marquei uma reunião com as voluntárias para explanar os objetivos do projeto e discutir de que forma cada um poderia colaborar para a sua concretização.

Tal fato indicou que a comunidade além de representar uma força social dinâmica, igualmente pode contribuir para a resolução de crises familiares, oportunizando aos seus membros um relacionamento entre si, de forma a influenciar uns aos outros, de maneira significativa, fazendo-os desenvolver a capacidade de tomar decisões adequadas, suportar tensões comuns da vida e expressar suas potencialidades ${ }^{4}$.

Durante essa reunião com os representantes da comunidade, surgiram novas estratégias para o projeto, dentre elas, uma senhora que faz parte da associação de moradores, assumiu a responsabilidade de divulgar o projeto, visto participar de várias atividades da comunidade, como missa aos domingos, novenas, reuniões da associação de pais e mestres, entre outras atividades. Para essa divulgação, a escola enviaria uma carta para os pais, por intermédio dos seus filhos. O atendimento dos pais no decorrer do projeto seria efetuado por mim e pela enfermeira voluntária, em horário de plantão todas as terças e quartas das 14 às 18 horas.

A equipe continuou a crescer, passando a contar com mais um profissional da área de saúde, uma psicóloga, moradora na comunidade. Ela se dispôs a atender os casos mais graves que necessitassem de encaminhamento, disponibilizando duas horas, nas terças, das 19 às 21 horas para os pais que fossem encaminhados pelo projeto. A participação dessa psicóloga, no projeto, veio preencher uma lacuna, pois nem todos os casos poderiam ser atendidos pelo enfermeiro, devido à sua competência profissional, principalmente aqueles em que houvesse a identificação de manifestações de comportamento sugestivo de sinais e sintomas de transtorno mental. Estes casos necessitam ser encaminhados para outros profissionais como psicólogo ou psiquiatra dependendo dos sintomas apresentados ${ }^{4}$. O projeto foi implementado com participação ativa da comunidade o que gera maior expectativa e possibilidade de êxito.

Em cada encontro do familiar com o enfermeiro, é discutido um plano terapêutico para a continuidade das ações, assegurando dia, horário e disponibilidade do profissional. Os assuntos mais comuns, trazidos para compartilhar durante os encontros com o enfermeiro foram: dificuldades de relacionamento com o filho e outros membros da família, baixo rendimento escolar, educação dos filhos, sexualidade, falta de autoridade dos pais e drogas.

Embora, estejamos com pouco tempo de implementação desse projeto, já se pode observar a importância da proposta pela adesão dos pais, da escola e da comunidade. Isso reafirma o pressuposto 
de que enfermeiro além de promover a saúde das pessoas, pode tentar mudar a realidade vivida de cada um. Observa-se, também que apesar do projeto estar em pleno desenvolvimento, os atendimentos realizados ainda estão em fase de construção de vínculos, pois seus participantes sentem a necessidade de criar um vínculo entre os pais e a comunidade escolar o qual possibilitaria melhor entrosamento e interação, rompendo a resistência dos pais em compartilhar suas dificuldades de relacionamento com os seus filhos, com pessoas estranhas.

\section{CONSIDERAÇÕES FINAIS}

Ao fazer a proposta à direção escolar, tinha consciência de que se tratava de um projeto desafiador. Isto fez com que houvesse uma maior dedicação de minha parte no que diz respeito ao estudo de temas como: adolescência, sexualidade e uso e abuso de drogas.

No momento em que ocorreu a decisão de trabalhar, pela primeira vez, com a relação de ajuda de Alfred Benjamin, no auxílio aos pais dos alunos com dificuldade de relacionamento interpessoal, eu não sabia como concretizaria, na prática, o processo de interação, conforme estabelece este autor. Porém, ao conhecer melhor os conteúdos da relação interpessoal, vislumbrei a possibilidade concreta do trabalho autônomo da enfermeira. Ainda que para mim, o conceito de ajuda tinha um significado teórico e parcial que, até então, não me permitia enxergar como seria a prática dessa ajuda.

O hábito tecnicista comumente permeia a prática dos profissionais da área de saúde e em decorrência disso se prioriza o fazer, a realização da técnica, muitas vezes, em detrimento do relacional. Entretanto, ao se trabalhar com a relação de ajuda, o enfermeiro deve lançar mão dos conhecimentos gerais de enfermagem e os específicos que envolvem ou emergem da atual situação, além de procedimentos éticos. Igualmente deve utilizar sua própria pessoa como instrumento de ajuda terapêutica, agindo de maneira sistematizada e empática diante da pessoa, que necessita de seus cuidados $^{4}$. No modelo de atenção psicossocial, o problema não deixa de ser considerado, porém, são colocados entre "parênteses" ou em "suspensão". Nessa perspectiva, quem ganha destaque ou assume o centro da atenção do cuidado é o ser humano, a pessoa que traz consigo sofrimentos e dúvidas. Cuidar, nessa concepção é valorizar o humano de cada ser, o seu existir ${ }^{11}$.

Nesse sentido, percebo ainda, no tocante ao aumento da competência profissional do enfermeiro, enfocando a relação de ajuda e o modelo de atenção psicossocial, que há um grande percurso a ser trilhado. No entanto, depois dessa implementação, sinto satisfação e tranqüilidade por saber que existem maneiras e recursos dos enfermeiros para ajudar os pais a enfrentarem as dificuldades encontradas no processo de vida de seus filhos.

Ressalto que o profissional de enfermagem possui o compromisso de trabalhar com a problemática das pessoas buscando solucioná-las em conjunto, dando seguimento aos cuidados e avaliando os resultados ${ }^{12}$.

Realizando um balanço geral desde o início do projeto, afirmo quão importante foram os encontros com os pais, alunos e professores dessa escola, pois senti que vivenciamos um processo conjunto de harmonia e crescimento, integrando a comunidade ao espaço escolar e favorecendo a interação entre pais, alunos, escola e enfermeiros.

\section{REFERÊNCIAS}

1. Priotto EM. Projeto "Despertar da Adolescência Atenção Integral na fase Adolescer" - Relato de Experiência. Cogitare Enfermagem, 2002; 7(1):55-60.

2. Travelbee J. Intervencion em enfermeria psiquiátrica. 2. ed. Cali: Organización Panamericana de la Salud; 1982.

3 Benjamin A. A entrevista de ajuda. 9. ed. São Paulo: Martins Fontes; 2001. 
4 Rodrigues ARF. Enfermagem psiquiátrica: saúde mental: prevenção e intervenção. São Paulo: EPU; 1996.

5 Zagonel IPS. O ser adolescente em transição exsistindo: um enfoque de cuidar-pesquisar sob a ótica da enfermagem. [tese]. Florianópolis (SC): Universidade Federal de Santa Catarina; 1998.

6 Brasil. Lei n. 8.069, de 13 de Julho de 1990. Dispõe sobre o estatuto da criança e do adolescente e da outras providências. Diário Oficial da República Federativa do Brasil, Brasília, 10 de janeiro de 1991.

7 Tiba I. Sexo e adolescência. 3. ed. São Paulo: Editora Ática; 1987.
8 Saito MI. Adolescência, cultura, vulnerabilidade e risco. Pediatria, 2000; 22 (3):217-9.

9 Cardoso CP, Cocco MIM. Projeto de vida de um grupo de adolescentes à luz de Paulo Freire. Rev Latino-Am Enferm 2003; 11(6): 778-85.

10 Laraia RB. Cultura: um conceito antropológico. 8. ed. Rio de Janeiro: Jorge Zahar; 1993.

11 Hiratorin K, Costa TL, Formoso GA, Silva SA. Educação em saúde como estratégia para garantir a dignidade da pessoa humana. Rev. Bras. Enferm 2004; 57(5):617-9.

12 Daniel LF. Atitudes interpessoais em enfermagem. São Paulo: EPU; 1983 